\title{
Abnormal Tryptophan Metabolism in Patients with Adult Celiac Disease, with Evidence for Deficiency of Vitamin $\mathrm{B}_{\boldsymbol{e}}$ *
}

\author{
O. Dhodanand Kowlessar, $\nmid$ Lorraine J. Haeffner $\ddagger$ and Gordon D. Benson $\S$ \\ (From the Department of Medicine, New York Hospital-Cornell Medical Center, \\ New York, N.Y.)
}

Increased urinary excretion of certain aromatic metabolites of tryptophan has been described in a wide variety of pathologic conditions: pyridoxine deficiency either primary or secondary to isoniazid or deoxypyridoxine (1) ; metabolic diseases such as in phenylketonuria (2), porphyria $(3,4)$, and Hartnup's disease (5); a variety of malignancies-metastatic malignant carcinoid (6), bladder carcinoma $(4,7)$, leukemia $(8)$, and lymphoma (8); mental disorders (4); pregnancy $(9,10)$; and collagen vascular diseases $(4,11)$.

Recently, elevated urinary levels of 5-hydroxyindoleacetic acid and indole-3-acetic acid have been found in symptomatic, untreated adult celiac disease with subsequent fall to normal during clinical and biochemical remission $(12,13)$. To study this abnormality further, we measured six urinary metabolites of tryptophan simultaneously in patients with adult celiac disease in various stages of their illness both before and after tryptophan loading. Also assessed was the role of vitamin $\mathrm{B}_{6}$ deficiency in the abnormal tryptophan metabolism of this disease.

* Submitted for publication November 5, 1963 ; accepted January 2, 1964.

Supported by U. S. Public Health Service research grant AM 03136-4, National Institute of Arthritis and Metabolic Diseases.

Presented in part at the 53rd Annual Meeting of the American Society for Clinical Investigation and American Federation for Clinical Research, April 1961, Atlantic City, N. J., and in part at the Gastroenterological Research Forum, May 1961, Chicago, Ill. Published in part in abstract form: J. clin. Invest. 1961, 40, 1055.

$\dagger, \ddagger$ Present address: Department of Medicine, Seton Hall College of Medicine and Dentistry, Medical Center, Jersey City, N. J.

§ Present address: Rutgers Medical School, New Brunswick, N. J.

\section{Methods}

Analytic procedures. The methods for the determination of urinary 5-hydroxyindoleacetic acid (5HIAA), total indole-3-acetic acid (IAA), indican (Ind), $\mathrm{ky}$ nurenine (Kyn), kynurenic acid (KA), and xanthurenic acid (XA) have been previously described (14-18). A Zeiss M4011 spectrophotometer with a fluorimetric attachment using filter $E$ was used for the quantitative fluorescent determinations of XA and KA. The urinary metabolites were further identified by two-dimensional paper chromatography according to Jepson (19), after which Erhlich's acidic p-dimethylaminobenzaldehyde in acetone was used to identify IAA, Ind, and 5HIAA; XA, KA, and Kyn were identified by their characteristic fluorescence under ultraviolet light. KA and Kyn were further identified by Ninhydrin-pyridine and XA by the sulfanilic acid reagent (19). From these studies, we were certain that the metabolites determined were actually present in the samples and that other substances that might give a specious color response were not present.

The above determinations were done on three consecutive 8-hour collections of urine for the following 24-hour periods: control, after loading with $4.0 \mathrm{~g}$ L-tryptophan in orange juice, and after reloading with $4.0 \mathrm{~g}$ L-tryptophan plus $180 \mathrm{mg}$ vitamin $\mathrm{B}_{6}$ intramuscularly ( $90 \mathrm{mg}$ im on 2 consecutive days). A repeat tryptophan load was performed on 2 untreated celiacs at the end of 1 week of oral tetracycline therapy $(500 \mathrm{mg}$ four times daily) to determine the effect of partial gut sterilization on the excretion of these metabolites.

Subjects. The study group consisted of 10 normal subjects and 21 patients with adult celiac disease; 5 of these patients were untreated, and 16 were studied on a gluten-free diet. All of the latter were in clinical remission, but only 3 had normal fat excretion at the time of the study.

The diagnosis of adult celiac disease was established in 17 patients with steatorrhea by the characteristic jejunal biopsies ("subtotal" villous atrophy), together with diminished D-xylose absorption, abnormal small bowel series, and salutary response to the gluten-free diet. Four patients who were not biopsied satisfied all of the other criteria. All studies were done on a metabolic ward. Each patient was carefully instructed in the method of 
$B_{6}$ DEFICIENCY AND ABNORMAL TRYPTOPHAN METABOLISM IN ADULT CELIACS

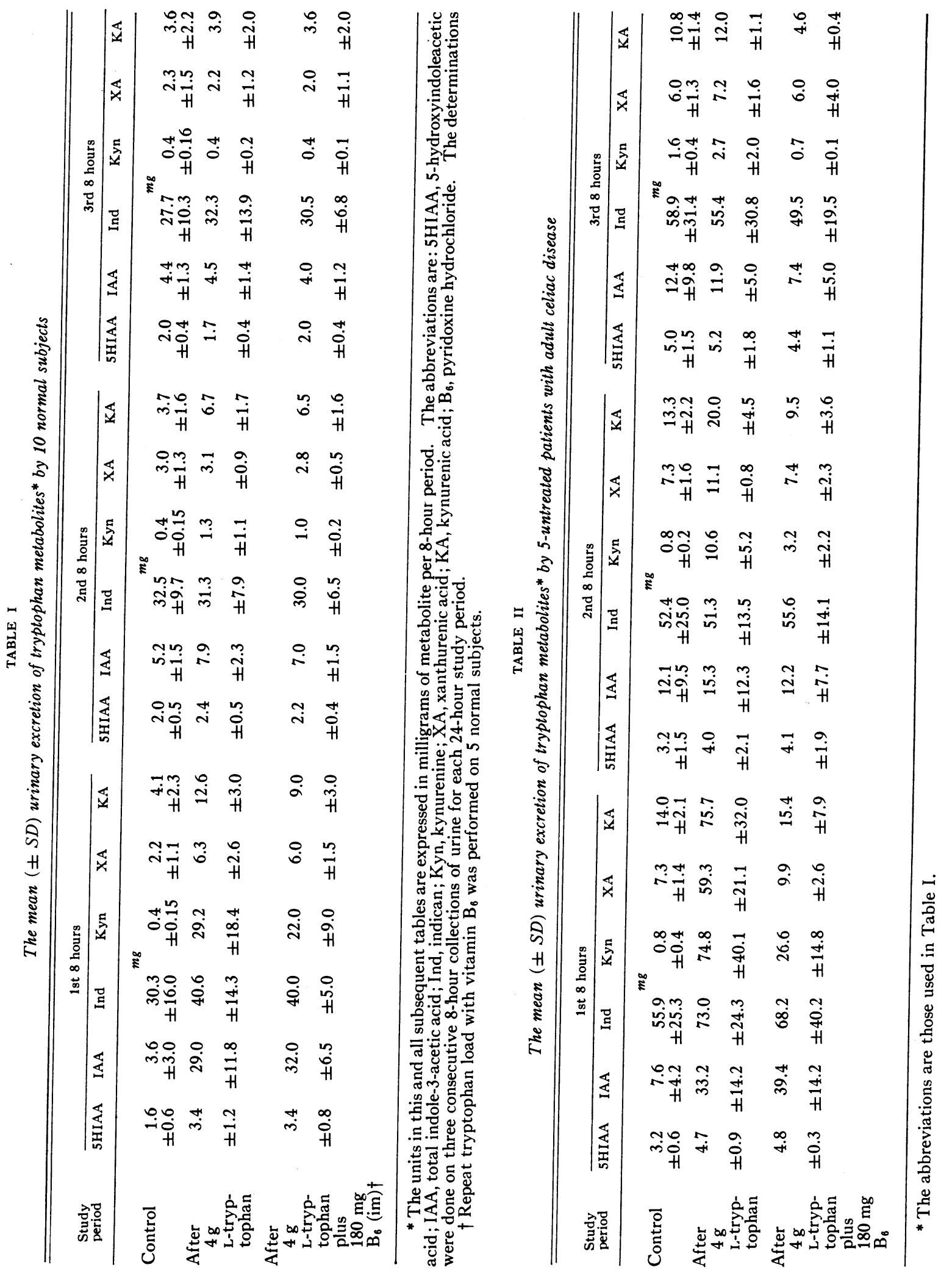


urine collections. During these periods bananas, tomatoes, avocados, eggplant, and prunes were excluded from their diets (20). All medications were withheld 48 hours before collection of specimens of urine and during the study period (21). The patients who were already on gluten-free diets continued their diets during the study.

Mean and standard deviation of the mean were calculated by standard statistical formulas. Statistical evaluation by means of a $t$ test was made by comparing the levels of excretion of tryptophan metabolites of the normal subjects with those of the patient groups during the first 8 hours of excretion. Probabilities less than 0.05 were considered to indicate a statistically significant difference.

\section{Results}

The mean $\pm \mathrm{SD}$, expressed in milligrams for each consecutive 8-hour excretion of Ind, IAA, 5HIAA, Kyn, XA, and KA before and after tryptophan loading, is shown in Tables I to IV for the control subjects and the patients with adult celiac diseases. The patient group is further subdivided into untreated patients (Table II), patients treated with a gluten-free diet but still excreting excessive fecal fat (Table III), and treated patients without steatorrhea on the diet (Table IV). Included in the tables are the mean levels of the various metabolites studied during the control period, after the ingestion of $4 \mathrm{~g}$ of L-tryptophan, and after $4 \mathrm{~g}$ of L-tryptophan plus $180 \mathrm{mg}$ of vitamin $\mathrm{B}_{6}$ (90 $\mathrm{mg}$ intramuscularly on 2 consecutive days).

Since the major changes in the excretion pattern of the various metabolites after the tryptophan load were noted in the first 8-hour collection, all reported results will refer primarily to this period.

Normal subjects and untreated adult celiac patients. The mean excretion during the first 8-hour control period by the normal subjects for Ind, IAA, 5HIAA, Kyn, XA, and KA was $30.3 \pm 16.0$, $3.6 \pm 3.0, \quad 1.6 \pm 0.6, \quad 0.4 \pm 0.15,2.2 \pm 1.1$, and $4.1 \pm 2.3 \mathrm{mg}$, respectively. The excretion of these metabolites by the untreated patients in the first 8 hours of their control period was significantly higher, being $55.9 \pm 25.3 \mathrm{mg}(0.05>\mathrm{p}>0.025)$, $7.6 \pm 4.2 \mathrm{mg}(0.05>\mathrm{p}>0.025), 3.2 \pm 0.6 \mathrm{mg}$ $(\mathrm{p}<0.001), 0.8 \pm 0.4 \mathrm{mg}(0.02>\mathrm{p}>0.01), \quad 7.3$ $\pm 1.4 \mathrm{mg}$ ( $\mathrm{p}<0.001)$, and $14.0 \pm 2.1 \mathrm{mg}(\mathrm{p}$ $<0.001$ ), respectively. After $4 \mathrm{~g}$ of L-tryptophan, there was an increase in all of the metabolites studied, but the increases in 5HIAA, Kyn, XA, and KA were highly significant in the patients, being $4.7 \pm 0.9 \mathrm{mg}(0.05>\mathrm{p}>0.025), 74.8 \pm$ $40.1 \mathrm{mg}(0.01>\mathrm{p}>0.005), 59.3 \pm 21.1 \mathrm{mg}(\mathrm{p}$ $<0.001)$, and $75.7 \pm 32.0 \mathrm{mg}(\mathrm{p}<0.001)$, respectively. After the im injection of vitamin $B_{6}$, the levels of Kyn, XA, and KA fell to $26.6 \pm$ $14.8,9.9 \pm 2.6$, and $15.4 \pm 7.9 \mathrm{mg}$, respectively, which are statistically not significant. The mean 5HIAA excretion after tryptophan plus vitamin $\mathrm{B}_{6}$ was still significantly elevated, being $4.8 \pm 0.3$ mg $(0.01>p>0.005)$.

Patients on gluten-free diet with steatorrhea. The first 8-hour control excretion levels of Ind, IAA, and 5HIAA were significantly higher than those of the normal subjects, being $48.1 \pm 20.2$ $\mathrm{mg}(0.05>\mathrm{p}>0.025), 6.4 \pm 2.4 \mathrm{mg}(0.025>\mathrm{p}$ $>0.02)$, and $3.7 \pm 0.9 \mathrm{mg}(\mathrm{p}<0.001)$, respectively. Kyn excretion was statistically the same as the normal subjects $(0.20>p>0.10)$, whereas $\mathrm{XA}$ and KA were significantly higher, being 5.3 $\pm 2.5 \mathrm{mg}(\mathrm{p}<0.001)$ and $10.4 \pm 2.9 \mathrm{mg}$ ( $\mathrm{p}$ $<0.001$ ), respectively. After tryptophan loading, a significant increase in 5HIAA, Kyn, XA, and KA excretion was noted, being $4.9 \pm 1.8 \mathrm{mg}$ $(0.005>\mathrm{p}>0.001), 82.1 \pm 36.4 \mathrm{mg}(\mathrm{p}<0.001)$, $41.4 \pm 10.5 \mathrm{mg}(\mathrm{p}<0.001)$, and $61.9 \pm 14.8 \mathrm{mg}$ ( $p<0.001)$, respectively. The repeat load of tryptophan plus vitamin $\mathrm{B}_{6}$ demonstrated a return to normal mean excretion levels of $\mathrm{Kyn}, \mathrm{XA}$, and $\mathrm{KA}$, being $30.2 \pm 12.2 \mathrm{mg}(0.20>\mathrm{p}>0.10)$, $7.7 \pm 2.6 \mathrm{mg}(0.20>\mathrm{p}>0.10)$, and $14.8 \mathrm{mg}$ $\pm 4.0 \mathrm{mg}(0.10>\mathrm{p}>0.05)$, respectively. 5HIAA excretion was still elevated after the repeat tryptophan load with vitamin $B_{6}$, being $5.4 \pm 1.0 \mathrm{mg}$ $(0.005>\mathrm{p}>0.001)$.

Patients on gluten-free diet without steatorrhea. The mean excretion during the first 8-hour control period of Ind, IAA, 5HIAA, and Kyn was statistically similar to the normal subjects, being $15.6 \pm 1.7 \mathrm{mg}(0.20>\mathrm{p}>0.10), 3.9 \pm 0.7 \mathrm{mg}$ ( $\mathrm{p}>0.90), 2.3 \pm 0.4 \mathrm{mg}(\mathrm{p}>0.05)$, and $0.4 \pm$ $0.05 \mathrm{mg}(\mathrm{p}>0.9)$, respectively. The XA and KA excretions were significantly higher than the normal subjects, being $4.5 \pm 0.8 \mathrm{mg}(0.01>\mathrm{p}$ $>0.005)$ and $19.1 \pm 3.5 \mathrm{mg}(\mathrm{p}<0.001)$, respectively. Statistically significant increases in Kyn, $\mathrm{XA}$, and KA were observed after the tryptophan load, the levels being $134.8 \pm 23.1 \mathrm{mg}(\mathrm{p}<0.001)$, $46.4 \pm 9.0 \mathrm{mg}(\mathrm{p}>0.001)$, and $93.6 \pm 15.0 \mathrm{mg}$ $(\mathrm{p}<0.001)$, respectively, with a prompt decrease 
$B_{6}$ DEFICIENCY AND ABNORMAL TRYPTOPHAN METABOLISM IN ADULT CELIACS

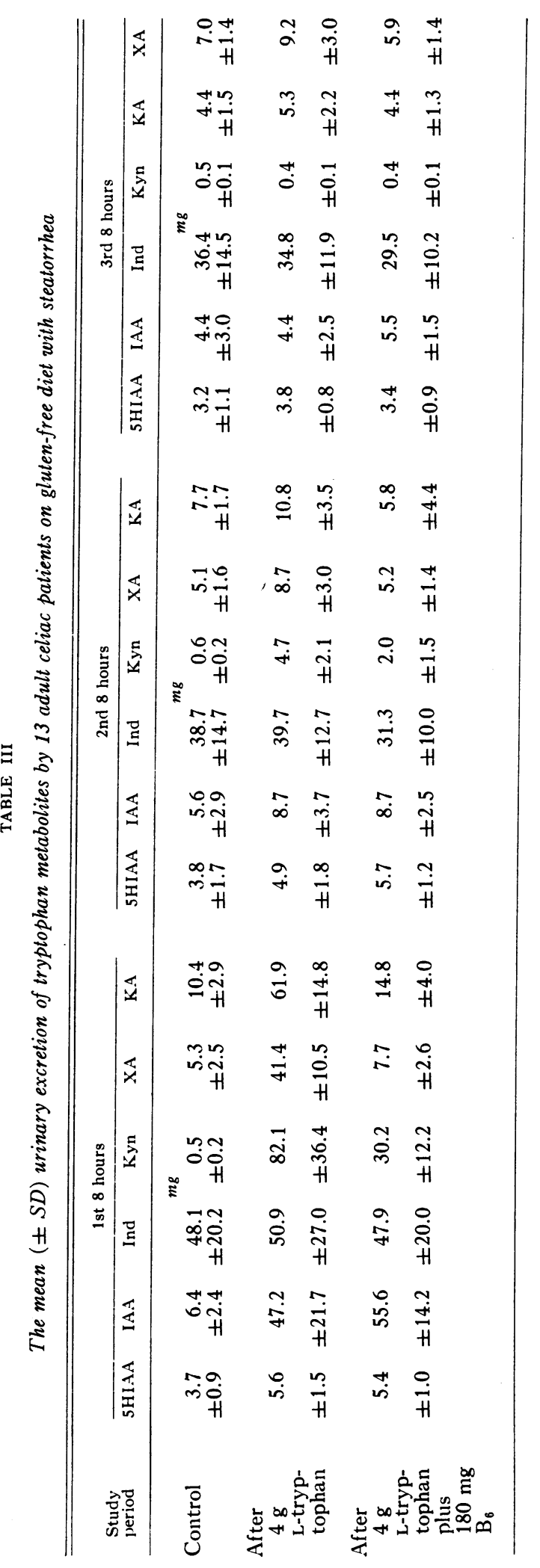

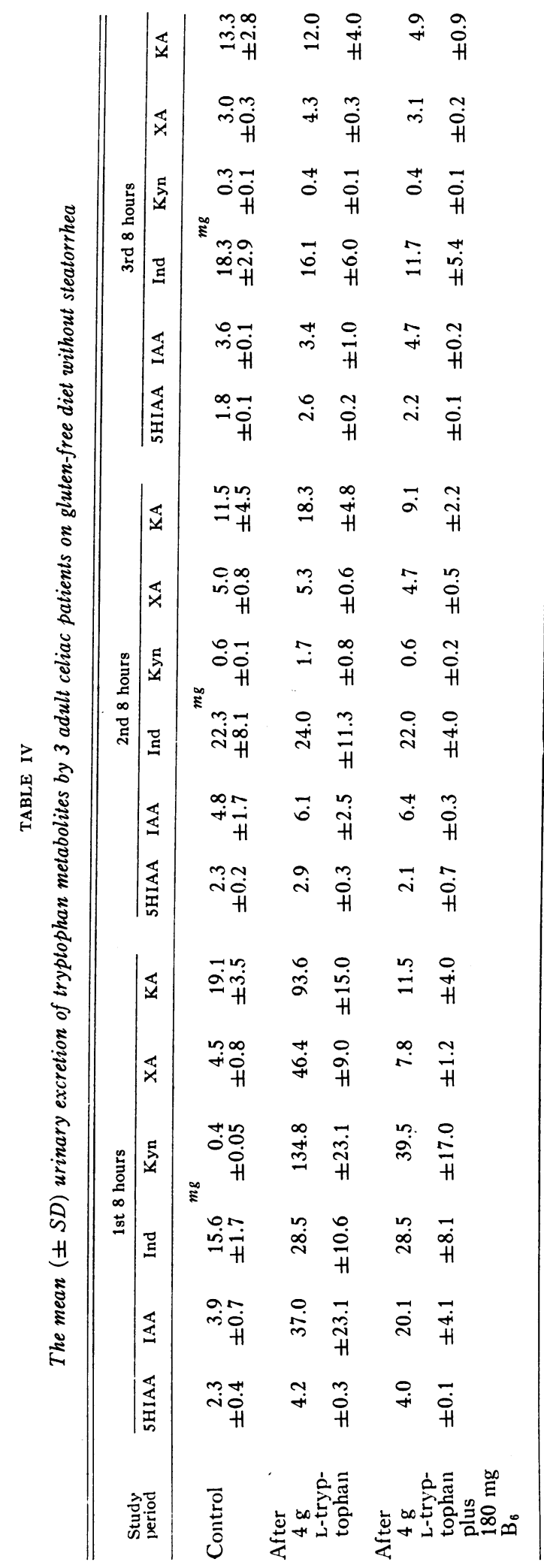




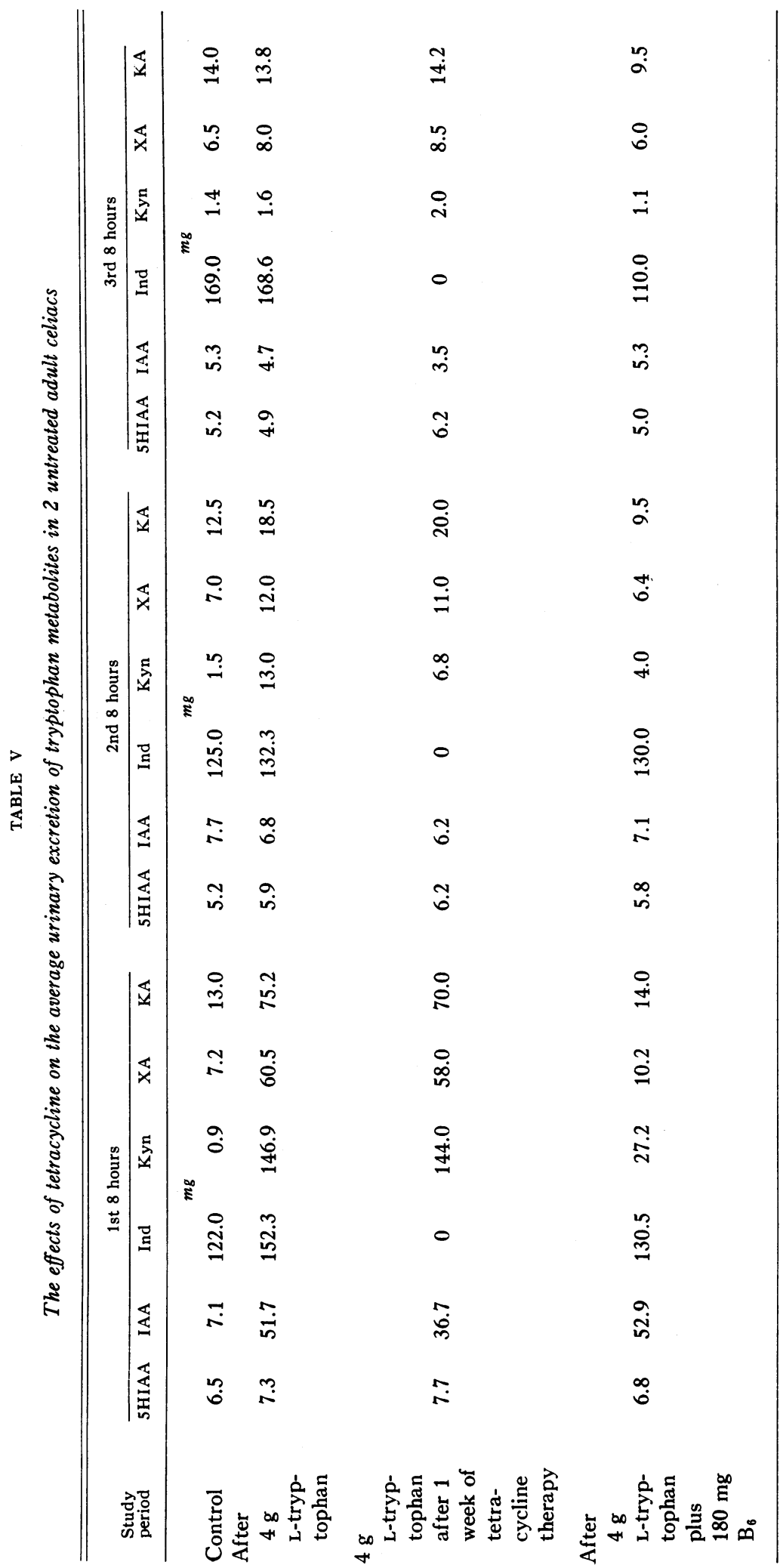


$B_{6}$ DEFICIENCY AND ABNORMAL TRYPTOPHAN METABOLISM IN ADULT CELIACS

to $39.5 \pm 7.0 \mathrm{mg}(0.10>\mathrm{p}>0.05), 7.8 \pm 1.2$ $\mathrm{mg}(0.40>\mathrm{p}>0.30)$, and $11.5 \pm 4.0 \mathrm{mg}(0.40>$ $\mathrm{p}>0.30)$, respectively, after the repeat tryptophan load with added $\mathrm{B}_{6}$.

Effects of tetracycline on the excretion of tryptophan metabolites in untreated patients. When 2 untreated patients were reloaded with $4 \mathrm{~g}$ of L-tryptophan while on $500 \mathrm{mg}$ of tetracycline four times daily for 1 week, the Ind excretion fell to zero for each consecutive 8-hour period, whereas IAA excretion fell from an average of 51.7 to $36.7 \mathrm{mg}$ during the first 8 hours. There was no decrease, however, in the excretion of $\mathrm{Kyn}, \mathrm{KA}$, $\mathrm{XA}$, and 5HIAA after the tryptophan load in these individuals (Table $\mathrm{V}$ ).

\section{Discussion}

The present quantitative results show that patients with untreated adult celiac disease as well as the treated patients with steatorrhea excrete increased amounts of indican, indole-3-acetic acid, 5-hydroxyindoleacetic acid, kynurenine, kynurenic acid, and xanthurenic acid. Patients who are treated with a gluten-free diet and who are in clinical and biochemical remission as judged by absence of steatorrhea, return of xylose absorption to normal, and evidence of regeneration of the mucosal villi of the jejunum, excrete Ind, IAA, 5HIAA, and Kyn normally ; however, their $\mathrm{KA}$ and XA levels remain elevated. On the other hand, when patients are loaded with $4 \mathrm{~g}$ of L-tryptophan orally, regardless of the stage of their disease, the excretion of XA, KA, and Kyn rises markedly.

The previously reported elevated base-line levels of urinary 5HIAA and IAA and indican in the untreated and treated symptomatic adult celiac patients have been confirmed in these studies (12, 13). It is of great interest that the patients on the gluten-free diet who are still having steatorrhea continue to excrete these substances abnormally. The increased excretion of IAA and IND is not specific for adult celiac disease, for we as well as others have observed increased levels of these metabolites of tryptophan in a variety of malabsorptive states, both intestinal and pancreatogenous (13).

The urinary indoxyl derivatives presumably are final excretory products formed in the liver from indole absorbed from the gut (22). In these patients it probably arises from coexistent alteration in gut bacterial flora and increased intraluminal amounts of protein and peptides containing tryptophan, both from undigested food and from protein weeping into the gut. The complete absence of indoxyl sulfate excretion by suppression of the gut flora by 1 week of tetracycline therapy despite feeding L-tryptophan speaks for alteration of a pathway involving action of bacteria. Of note, the indicanuria returns to its high level a few days after cessation of the antibiotics (Table V). A change in the bacterial flora seems the most likely mechanism in view of the return to normal levels in patients who are in clinical and biochemical remission on a gluten-free diet and who no longer have stasis or distension.

IAA excretion is clearly elevated in patients with untreated celiac disease as well as the patients on gluten-free diet who still have steatorrhea. Part of this abnormal excretion, like indican, may well be related to abnormal gut flora as evidenced by the decrease in IAA after tetracycline when tryptophan is added. That the IAA did not fall to zero suggests that the metabolism of tryptophan to IAA is not purely dependent on altered bacterial flora but that other pathways are also utilized and is also related to abnormal metabolism of absorbed tryptophan by the tissues (15).

5HIAA excretion is elevated in patients with adult celiac disease in the untreated and treated states with steatorrhea; these elevated levels return to normal with the clinical and biochemical remission that may follow elimination of gluten. Administration of tetracycline, however, does not affect these increased levels, suggesting that they are not solely dependent on bacterial action. As seen in Tables I and IV, after loading with $4 \mathrm{~g}$ of L-tryptophan, both the normal subjects and the adult celiac patients on a gluten-free diet without steatorrhea show a similar increase in 5HIAA excretion $(p>0.25)$. However, there is a significant increase in the excretion of 5HIAA after tryptophan loading in the untreated celiac patients and the treated patients with steatorrhea $(0.005>$ p >0.001) (Tables I and III). Scriver (23), using D-L-tryptophan and a semiquantitative technique, demonstrated a $100 \%$ increase in 5HIAA excretion after the D-L-tryptophan load in a 
patient with adult celiac disease. 5HIAA can also arise from $\mathrm{D}$-5-hydroxytryptophan by the action of D-amino acid oxidase forming the keto acid, 5-hydroxyindolepyruvic acid, which could then be decarboxylated to 5-hydroxyindoleacetic acid. Defective transamination or conjugation of the keto acid from D-5-hydroxytryptophan could thus result in a higher percentage of conversion of 5hydroxyindoleacetic acid and thus account for Scriver's findings. Our observations indicate that adult celiac patients with steatorrhea have an augmented shunt of the serotonin to 5HIAA pathway after L-tryptophan loading.

Vitamin $B_{6}$ is required for the enzymatic conversion of 5-hydroxytryptophan to 5-hydroxytryptamine (serotonin) by 5 -hydroxytryptophan decarboxylase (Figure -1). In view of this requirement, one would expect a lowered base-line excretion of 5-hydroxyindoleacetic acid in $\mathrm{B}_{6^{-}}$ deficient subjects (24). Our studies demonstrate an increased excretion of 5HIAA in the untreated and treated celiac patients with steatorrhea, which is further increased by the oral ingestion of L-tryptophan. When im $\mathrm{B}_{6}$ is given with a repeat tryptophan load to the same group of patients, there is a significant increase in the excretion of 5HIAA. These findings suggest that if these patients did not have a $B_{6}$ deficiency, the base-line 5HIAA excretion might have been greater.

Under normal circumstances, kynurenine and hydroxykynurenine are cleaved by the enzyme kynureninase to alanine plus anthranilic or 3hydroxyanthranilic acid, respectively (Figure 1). Because pyridoxal phosphate $\left(B_{6}\right)$ is required for action of this enzyme, the metabolism of both kynurenine and hydroxykynurenine is altered in pyridoxine deficiency. These compounds appear to be shunted through the kynurenine transaminase pathway with the formation of the corresponding alpha-keto acids. These cyclize spontaneously to kynurenic acid and xanthurenic acid, as is evidenced by the finding in the urine of pyridoxine-deficient animals of large amounts of $\mathrm{Kyn}, \mathrm{KA}$, and XA, as well as other tryptophan metabolites (25).

The results obtained in these studies indicate that patients with adult celiac disease, whether treated or not, fail to metabolize an oral L-tryptophan load normally. This metabolic failure is characterized by increased excretion of Kyn, XA, and $\mathrm{KA}$, findings that might be expected in animals and human subjects with a deficiency of $B_{6}$. This viewpoint is further strengthened by the return to near normal levels of these urinary metabolites after large doses of im $\mathrm{B}_{6}$ are administered simultaneously with the repeat tryptophan load.

The question arises as to the mechanism responsible for the deranged tryptophan metabolism in adult celiac disease. The calculated value of daily intake of $B_{6}$ in the subjects under study is approximately $2.5 \mathrm{mg}(26)$, whereas the daily re-

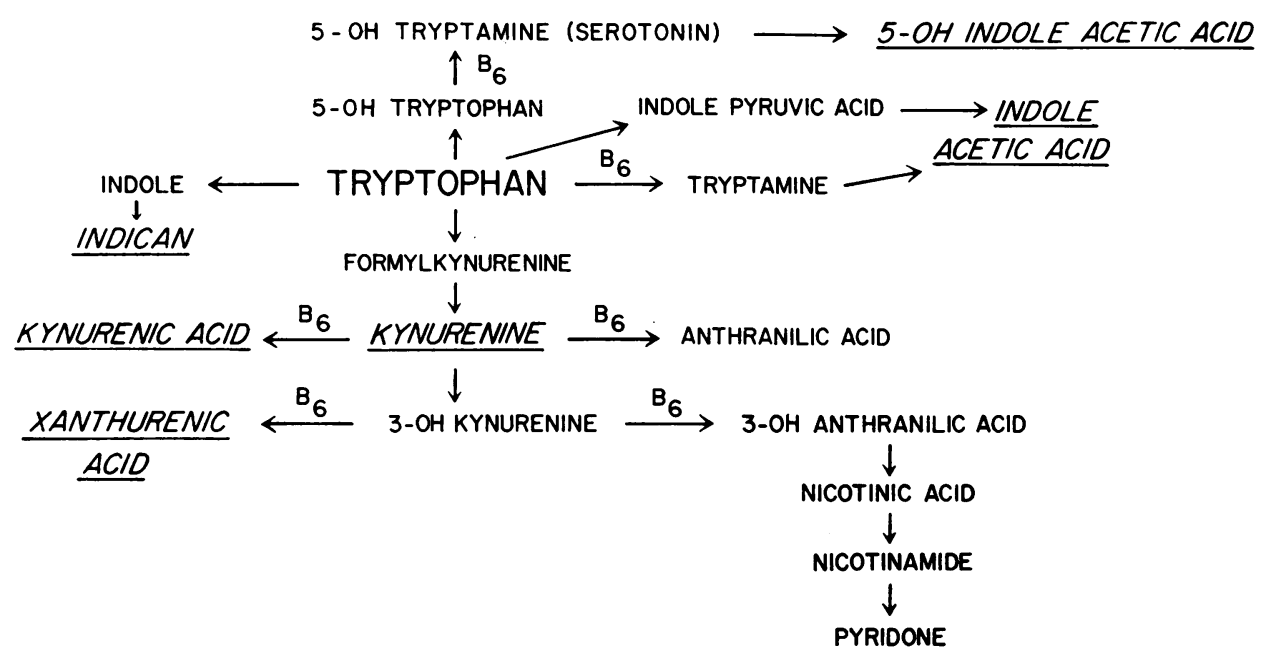

Fig. 1. Main metabolic pathways of tryptophan. The underlined metabolites were those studied. Pyridoxine $\left(B_{6}\right)$, in the form of pyridoxal phosphate, has been reported to function in the areas indicated on the metabolic map. 
quirement for normal adults is estimated to be $1.5 \mathrm{mg}$ (27). Perhaps this approximated oral intake of $\mathrm{B}_{6}$ may be inadequate for a patient with malabsorption secondary to adult celiac disease. This explanation may suffice for the patients with obvious malabsorption, but it does not explain why the three patients in clinical and biochemical remission are also deficient in $B_{6}$, as judged by their failure to metabolize a tryptophan load normally. Either the requirement for $\mathrm{B}_{6}$ continues to be excessive in spite of remission, or $B_{6}$ continues to be malabsorbed. Although $4 \mathrm{~g}$ of $\mathrm{L}-$ tryptophan probably represents about six times the routine daily intake of this amino acid for any of the patients studied, Wachstein and Loebel (28) have suggested that a relative pyridoxine deficiency may be made manifest after a tryptophan load test by stressing a number of enzyme-coenzyme systems in tryptophan metabolism.

Failure of $B_{6}$ to be incorporated in the enzyme systems required for normal tryptophan metabolism may contribute to its abnormal metabolism. However, when pyridoxine was administered intramuscularly to our patients, biochemical response to tryptophan loading was normal, indicating that availability of $\mathrm{B}_{6}$ was the limiting factor for normal tryptophan metabolism in the patients with adult celiac disease.

All of the celiac patients in the untreated group, as well as some of the patients on the gluten-free diet who were still having steatorrhea, demonstrated superficial scaling of the skin and lesions around the eyes and mouth, with fissures at the angles of the mouth, lateral canthi of the eyes, and sore, reddened tongues. These findings can be seen in vitamin $\mathrm{B}_{6}$ deficiency but are also present as manifestations of other $\mathrm{B}$ complex deficiencies (29). Dramatic relief of these symptoms was obtained in many of these patients after administration of vitamin $B_{6}$ parenterally during the repeat tryptophan load and orally $(10 \mathrm{mg}$ daily) for a few weeks thereafter. Many of the other manifestations of $B_{6}$ deficiency were absent, but it is known from experimentally induced human pyridoxine deficiency that biochemical abnormalities, particularly the response to tryptophan loading, can be demonstrated before symptoms have become manifest.

If the thesis is acceptable that patients who fail to metabolize a tryptophan load normally are
$B_{6}$ deficient, then the results of this study are the first clear-cut evidence of $B_{6}$ deficiency in adult celiac disease. These findings do not agree with the observations of Girdwood (30), who noted normal absorption of $B$ complex vitamins, including $\mathrm{B}_{6}$, in celiac disease. Recently, however, Booth, Brain, and Stewart (31) have shown that some patients with celiac disease may malabsorb tritium-labeled pyridoxine.

Finally, it is possible that Price's explanation (4) for the finding of abnormal tryptophan metabolism in patients with bladder tumors is applicable to our findings, namely that patients with adult celiac disease may have an abnormal requirement for vitamin $B_{6}$ related to unknown genetic factors. This may be quite pertinent, in view of the observations of Boyer and Andersen (32) and Carter, Sheldon, and Walker (33) that celiac disease is an inheritable disorder.

Regardless of the mechanism of the abnormal response of these patients to a tryptophan load, it would appear justifiable to suggest that they be treated with $\mathrm{B}_{6}$ in addition to the gluten-free diet. Furthermore, Fletcher and McCririck (34) have raised the interesting question whether the glutenfree diet prescribed for patients with adult celiac disease may not be lacking, especially if intake of milk is inadequate, in essential nutrients such as members of the $\mathrm{B}$ complex family.

\section{Summary}

The excretion of the metabolites of tryptophan -5-hydroxyindoleacetic acid, indole-3-acetic acid, indican, kynurenine, xanthurenic acid, and kynurenic acid-was quantitatively determined in 10 normal subjects and in 21 patients wtih adult celiac disease. Five of the latter group were untreated, and 16 were studied on a gluten-free diet. The determinations were done on three consecutive 8-hour collections of urine for the following 24-hour periods: control, after loading with $4 \mathrm{~g}$ L-tryptophan, and after reloading with 4 g L-tryptophan plus $180 \mathrm{mg}$ vitamin $\mathrm{B}_{6}$ intramuscularly (90 $\mathrm{mg}$ im on 2 consecutive days).

Elevated urinary levels of 5-hydroxyindoleacetic acid, indole-3-acetic acid, and indican were found in the untreated and treated celiac patients with steatorrhea, whereas normal levels of these metabolites were obtained in the treated patients 
without steatorrhea. Furthermore, after loading with L-tryptophan the untreated and treated patients with steatorrhea showed a significant increase in their 5-hydroxyindoleacetic acid excretion, suggesting that this group of patients has an augmented shunt of the serotonin to 5-hydroxyindoleacetic acid pathway.

Tetracycline eliminated the elevated levels of indican excretion in 2 untreated patients with celiac disease, even after the tryptophan load, suggesting that these elevated levels were due to the increased breakdown of tryptophan by gut bacteria.

Patients with adult celiac disease regardless of the stage of their disease fail to metabolize an oral tryptophan load normally. This metabolic failure is characterized by significant increases in the excretion of kynurenine, xanthurenic acid, and kynurenic acid, findings seen in human subjects with a deficiency of vitamin $B_{6}$. This is the first clear-cut evidence for $\mathrm{B}_{6}$ deficiency in adult celiac disease, and our results suggest that these patients should be given supplementary vitamin $B_{6}$.

\section{References}

1. Price, J. M., R. R. Brown, and F. C. Larson. Quantitative studies on human urinary metabolites of tryptophan as affected by isoniazid and deoxypyridoxine. J. clin. Invest. 1957, 36, 1600.

2. Pare, C. M. B., M. Sandler, and R. S. Stacey. Decreased 5-hydroxytryptophan decarboxylase activity in phenylketonuria. Lancet 1958, 2, 1099.

3. Price, J. M., R. R. Brown, and H. A. Peters. Tryptophan metabolism in porphyria, schizophrenia, and a variety of neurologic and psychiatric diseases. Neurology (Minneap.) 1959, 9, 456.

4. Price, J. M. Disorders of tryptophan metabolism. Univ. Mich. med. Bull. 1958, 24, 461.

5. Milne, M. D., M. A. Crawford, C. B. Girão, and L. W. Loughridge. The metabolic disorder in Hartnup disease. Quart. J. Med. 1960, 29, 407.

6. Sjoerdsma, A., H. Weissbach, and S. Udenfriend. Clinical, physiologic and biochemical study of patients with malignant carcinoid (argentaffinoma). Amer. J. Med. 1956, 20, 520.

7. Boyland, E., and D. C. Williams. The metabolism of tryptophan. 2. The metabolism of tryptophan in patients suffering from cancer of the bladder. Biochem. J. 1956, 64, 578.

8. Musajo, L., C. A. Benassi, and A. Parpajola. Excretion and isolation of kynurenine and 3-hydroxykynurenine from human pathological urine. Clin. chim. Acta 1956, 1, 229.
9. Wachstein, M., and A. Gudaitis. Disturbance of vitamin $B_{6}$ metabolism in pregnancy. J. Lab. clin. Med. 1952, 40, 550.

10. Brown, R. R., M. J. Thornton, and J. M. Price. The effect of vitamin supplementation on the urinary excretion of tryptophan metabolites by pregnant women. J. clin. Invest. 1961, 40, 617.

11. Price, J. M., R. R. Brown, J. G. Rukavina, C. Mendelson, and S. A. M. Johnson. Scleroderma (acrosclerosis). II. Tryptophan metabolism before and during treatment by chelation (EDTA). J. invest. Derm. 1957, 29, 289.

12. Kowlessar, O. D., R. C. Williams, D. H. Law, and M. H. Sleisenger. Urinary excretion of 5-hydroxyindoleacetic acid in diarrheal states, with special reference to nontropical sprue. New Engl. J. Med. 1958, 259, 340.

13. Haverback, B. J., B. Dyce, and H. V. Thomas. Indole metabolism in the malabsorption syndrome. New Engl. J. Med. 1960, 262, 754.

14. Udenfriend, S., E. Titus, and H. Weissbach. The identification of 5-hydroxy-3-indoleacetic acid in normal urine and method for its assay. J. biol. Chem. 1955, 216, 499.

15. Weissbach, H., W. King, A. Sjoerdsma, and S. Udenfriend. Formation of indole-3-acetic acid and tryptamine in animals. A method for estimation of indole-3-acetic acid in tissues. J. biol. Chem. 1959, 234, 81.

16. Meikeljohn, A. P., and F. P. Cohen. The quantitative determination of indoxyl compounds in urine. J. Lab. clin. Med. 1942, 27, 949.

17. Tompsett, S. L. The determination in urine of some metabolites of tryptophan-kynurenine, anthranilic acid and 3-hydroxyanthranilic acid and reference to the presence of $\mathrm{O}$-aminophenol in urine. Clin. chim. Acta 1959, 4, 411.

18. Satoh, K., and J. M. Price. Fluorometric determination of kynurenic acid and xanthurenic acid in human urine. J. biol. Chem. 1958, 230, 781.

19. Jepson, J. B. Indoles and Related Ehrlich Reactors: Chromographic and Electrophoretic Techniques, 2nd ed., I. Smith, Ed. New York, Interscience, 1961, vol. 1, pp. 186, 196.

20. Udenfriend, S., W. Lovenberg, and A. Sjoerdsma. Physiologically active amines in common fruits and vegetables. Arch. Biochem. 1959, 85, 487.

21. Ross, G., I. B. Weinstein, and B. Kabakow. 'Influence of phenothiazine and some of its derivatives on the determination of 5-hydroxyindoleacetic acid in urine. Clin. Chem. 1958, 4, 66.

22. Stoppani, A. O. M. Precursors of indoxyl. J. biol. Chem. 1945, 157, 1.

23. Scriver, C. R. Abnormalities of tryptophan metabolism in a patient with malabsorption syndrome. J. Lab. clin. Med. 1961, 58, 908.

24. Scriver, C. R., and J. H. Hutchison. The vitamin $B_{6}$ deficiency syndrome in human infancy: bio- 
chemical and clinical observations. Pediatrics 1963, 31, 240.

25. Dalgliesh, C. E. The relation between pyridoxine and tryptophan metabolism, studied in the rat. Biochem. J. 1952, 52, 3.

26. Wohl, M. G., and R. S. Goodhart. Modern Nutrition in Health and Disease, 2nd ed. Philadelphia, Lea \& Febiger, 1960, p. 349.

27. Williams, R. J. The approximate vitamin requirements of human beings. J. Amer. med. Ass. 1942, $119,1$.

28. Wachstein, M., and S. Lobel. The relation between tryptophan metabolism and vitamin $B_{6}$ in various diseases as studied by paper chromatography. Amer. J. clin. Path. 1956, 26, 910.

29. Gyorgy, P. Pyridoxine and related compounds. Requirements and factors influencing them in man in The Vitamins, Chemistry, Physiology, Pathol- ogy, W. H. Sebrell, Jr., and R. S. Harris, Eds. New York, Academic Press, 1954, vol. 3, p. 282.

30. Girdwood, R. H. Absorption in sprue of vitamins of the B complex. Lancet 1956, 2, 700.

31. Booth, C. C., M. C. Brain, and J. S. Stewart. The absorption of tritium-labelled pyridoxine (abstract). Amer. J. dig. Dis. 1962, 7, 973.

32. Boyer, P. H., and D. H. Andersen. A genetic study of celiac disease. Incidence of celiac disease, gastrointestinal disorders, and diabetes in pedigrees of children with celiac disease. Amer. J. Dis. Child. 1956, 91, 131.

33. Carter, C., W. Sheldon, and C. Walker. The inheritance of coeliac disease. Ann. hum. Genet. 1959, 23, 266.

34. Fletcher, R. F., and M. Y. McCririck. Gluten-free diets. Brit. med. J. 1958, 2, 299. 